\title{
MÉTODOS ALTERNATIVOS DO TESTE DE FRIO PARA AVALIAÇÃO DO VIGOR DE SEMENTES DE MILHO'
}

\author{
Roseli Fátima Caseiro ${ }^{2,4 *}$; Júlio Marcos Filho 3,5 \\ ${ }^{2}$ Pós-Graduanda do Depto. de Produção Vegetal - USP/ESALQ. \\ ${ }^{3}$ Depto. de Produção Vegetal - USP/ESALQ, C.P. 9 - CEP: 13418-900 - Piracicaba, SP. \\ ${ }^{4}$ Bolsista CAPES. \\ ${ }^{5}$ Bolsista CNPq. \\ *Autor correspondente <rfcaseir@carpa.ciagri.usp.br>
}

\begin{abstract}
RESUMO: O presente trabalho teve como objetivo básico estudar comparativamente quatro métodos para a condução do teste de frio, visando a avaliação do potencial fisiológico das sementes de milho. Para tanto, foram utilizados dois cultivares de milho (AG 3010 e AG 5011), cada um representado por 5 lotes com potenciais fisiológicos distintos. Amostras de sementes de todos os lotes foram submetidas a quatro procedimentos do teste de frio, a saber: "terra" (mistura de terra e areia) em caixas empilhadas (método tradicional); "terra" em caixas dispostas lado a lado; bandeja com "terra"; bandeja com "terra" + papel toalha. Estes procedimentos foram comparados com os testes de germinação padrão, envelhecimento acelerado e emergência das plântulas em campo. O teste de frio em bandeja oferece maior facilidade para padronização e permite a obtenção de resultados mais consistentes do que o teste de frio utilizando-se "terra" em caixas, inclusive quanto à relação com a emergência das plântulas em campo.
\end{abstract}

Palavras-chaves: Zea mays, semente, análise, potencial fisiológico, teste de frio, substrato

\section{ALTERNATIVE METHODS OF THE COLD TEST FOR EVALUATION OF CORN SEED VIGOR}

\begin{abstract}
This research was conducted with the objective of comparing different procedures of the cold test to evaluate corn seed vigor. Two cultivars (AG 3010 and AG 5011) represented by 5 lots each were used. Seed samples of all lots were submitted to four procedures of the cold test: stacked deep-box (Brazilian traditional method), deep-box disposed side by side, tray with soil and tray with soil + paper towel, in cold chamber at $10^{\circ} \mathrm{C}$ for seven days followed by germination at $25^{\circ} \mathrm{C}$. Those procedures were also compared with germination, accelerated aging and seedling field emergence tests. The cold test in tray exhibited a great level of standardization than the procedure known as deep-box, allowing for more consistent results and a closer relationship to seedling field emergence.

Key words: Zea mays, seed analysis, physiological quality, cold test, substrate
\end{abstract}

\section{INTRODUÇÃO}

O teste de frio é um dos mais antigos e populares testes para avaliação do vigor de sementes. Foi desenvolvido, inicialmente, para avaliar o potencial fisiológico de sementes de milho, procurando simular condições desfavoráveis (excesso de água, baixas temperaturas e ocorrência de fungos do solo) que ocorrem, com freqüência, durante a época de semeadura na área denominada Cinturão do Milho, nos EUA (Cícero \& Vieira, 1994). A combinação entre alta umidade e baixa temperatura do solo tem sido associada com o desempenho deficiente de lotes de sementes, especialmente em regiões de clima temperado, onde é freqüente a instalação de lavouras de milho no início da primavera (AOSA, 1983; Hampton \& TeKrony, 1995).

Além de avaliar o potencial de desempenho das sementes em campo e selecionar lotes para semeadura, esse teste pode ser usado para avaliar a eficiência de fungicidas, constituir parâmetro auxiliar para a seleção de materiais genéticos (em função da habilidade para germinar em solo úmido e frio), avaliar a deterioração resultante do armazenamento prolongado e efeitos de danos mecânicos. Também tem sido usado para avaliar o vigor de sementes de soja, algodão, sorgo e outras espécies (Hampton \& TeKrony, 1995).

No Brasil, tem sido utilizado por empresas produtoras de sementes, principalmente nos estados do sul e sudeste, onde lavouras de algodão, milho e soja podem ser semeadas entre o início do mês de setembro e meados de outubro. Nessa época, é comum a queda acentuada da temperatura e, dependendo do nível de vigor dos lotes de sementes, podem ser verificados sérios problemas para a emergência das plântulas em campo (Krzyzanowski et al., 1991).

O Comitê de Vigor da Association of Official Seed Analysts (AOSA, 1983) descreve procedimentos para a condução desse teste nos EUA; no entanto, o mesmo não tem sido padronizado entre diferentes laboratórios, que geralmente conduzem suas próprias versões do teste.

Parte da Dissertação de Mestrado da primeira autora apresentada à USP/ESALQ - Piracicaba, SP.

Scientia Agricola, v.57, n.3, p.459-466, jul./set. 2000 
Essa diversidade de métodos tem contribuído para a desuniformidade dos resultados obtidos (Burris \& Navratil, 1979).

No Brasil, também são encontradas variações da metodologia (Krzyzanowski et al., 1991; Cícero \& Vieira, 1994; Dias \& Barros, 1995), embora a maioria das análises seja conduzida utilizando-se a metodologia de "terra" em caixa. O método da bandeja praticamente não tem sido reconhecido no Brasil, embora seja o procedimento mais recomendado internacionalmente. Este método pode oferecer maior facilidade de padronização, controle mais adequado do umedecimento do substrato e, também, mostrar relação consistente com a emergência das plântulas em campo (Burris, 1990).

O presente trabalho teve a finalidade de estudar comparativamente as metodologias de "terra" em caixa e em bandeja, procurando verificar se a utilização dessa alternativa pode favorecer a reprodutibilidade dos resultados e, conseqüentemente, a confiabilidade das informações obtidas. O objetivo básico foi o de selecionar um procedimento que permita atingir padronização mais consistente, em relação à que tem sido obtida com os procedimentos habitualmente adotados no Brasil.

\section{MATERIAL E MÉTODOS}

O presente trabalho foi conduzido no Laboratório de Análise de Sementes do Departamento de Produção Vegetal da Escola Superior de Agricultura "Luiz de Queiroz" (USP/ESALQ). Utilizaram-se sementes de milho do híbrido AG 3010 (peneira 22M) e AG 5011 (peneira 22L), cada um representado por 5 lotes com potencial fisiológico distinto. Amostras de sementes de todos os lotes foram submetidas aos testes de frio (quatro procedimentos), germinação padrão, envelhecimento acelerado e emergência das plântulas em campo. Para cada teste foram utilizadas 4 repetições de 50 sementes de cada lote e cultivar. Os testes foram realizados duas vezes, com intervalo de 30 a 45 dias, para a verificação da precisão dos resultados.

Grau de umidade: a determinação foi efetuada de acordo com as Regras para Análise de Sementes (Brasil, 1992), utilizando-se o método da estufa, a $105^{\circ} \mathrm{C} \pm 3^{\circ} \mathrm{C}$ por 24 horas, com duas repetições para cada lote.

Germinação padrão: conduzido de acordo com as Regras para Análise de Sementes (Brasil, 1992), utilizando-se rolos de papel toalha, a $25^{\circ} \mathrm{C}$. O volume de água utilizado para embebição foi equivalente a 2,5 vezes o peso do substrato. As contagens foram realizadas aos 4 e 7 dias após a semeadura.

Envelhecimento acelerado: foram utilizadas caixas plásticas adaptadas, funcionando como compartimentos individuais (mini câmaras). Em cada caixa, foram colocados $40 \mathrm{ml}$ de água. As sementes foram distribuídas uniformemente sobre a tela de alumínio, colocada no interior de cada caixa, formando uma camada única. As caixas plásticas foram tampadas e mantidas em câmara de envelhecimento (tipo B.O.D) regulada a $41^{\circ} \mathrm{C}\left( \pm 0,3^{\circ} \mathrm{C}\right)$, durante 96 horas (AOSA, 1983). Após esse período, as sementes foram colocadas para germinar a $25^{\circ} \mathrm{C}$ e avaliadas 4 dias após a semeadura. Os resultados foram expressos em porcentagem de plântulas normais para cada lote e cultivar.

Emergência das plântulas em campo: conduzida mediante delineamento blocos ao acaso. Cada repetição foi representada por uma linha de $4 \mathrm{~m}$ de comprimento, onde foram distribuídas 50 sementes, espaçadas entre si de $8 \mathrm{~cm}$, em sulcos com cerca de $7 \mathrm{~cm}$ de profundidade e cobertas com, aproximadamente, $3 \mathrm{~cm}$ de terra. O espaçamento entre linhas foi de $40 \mathrm{~cm}$. Aos 14 dias após a semeadura, foi efetuada a contagem, expressando-se os resultados em percentagem de plântulas normais.

Teste de frio com "terra" em caixas empilhadas: cada caixa utilizada $(47 \times 30 \times 11 \mathrm{~cm})$ foi dividida em quatro compartimentos, cada um destinado à distribuição de 50 sementes. Como substrato, foram utilizados aproximadamente $16 \mathrm{~kg}$ da mistura terra e areia (chamada de "terra" no presente trabalho), na proporção 3:1 (3 partes de areia para 1 parte de terra), colocada nas caixas para, em seguida, proceder-se à semeadura e à cobertura das sementes com 2 a $3 \mathrm{~cm}$ do mesmo substrato. A terra foi coletada de área anteriormente cultivada com milho. A irrigação baseou-se no ajuste da disponibilidade de água do substrato para $60 \%$ da capacidade de retenção, cálculo efetuado de acordo com as Regras para Análise de Sementes (Brasil, 1992). Ao serem colocadas na câmara fria, as caixas foram superpostas formando pilhas. $O$ resfriamento foi conduzido a $10^{\circ} \mathrm{C}$, durante 7 dias e, em seguida, a germinação realizada a $25^{\circ} \mathrm{C}$ foi avaliada após 7 dias (na primeira época), computando-se a porcentagem de plântulas normais para cada lote e cultivar. Na segunda época, houve queda da temperatura ambiente, durante o período de germinação das sementes; por esse motivo, as contagens de plântulas normais foram realizadas aos 8 dias.

Teste de frio com "terra" em caixas dispostas lado a lado: o substrato, os procedimentos para a distribuição das sementes e o ajuste da disponibilidade de água foram os mesmos relatados no ítem anterior. Neste caso, a "terra" e a água foram pré-resfriadas a $10^{\circ} \mathrm{C}$ e, as caixas, dispostas lado a lado na câmara fria. $O$ resfriamento e a germinação foram conduzidos da mesma forma já descrita.

Teste de frio em bandejas, utilizando-se "terra" como substrato: foram utilizadas bandejas de plástico de $34 \mathrm{x}$ $23 \times 7 \mathrm{~cm}$, com $1 \mathrm{~kg}$ de "terra". Em cada bandeja foram distribuídas duas repetições de 50 sementes, em seguida 
cobertas com $1 \mathrm{~kg}$ do mesmo substrato. A disponibilidade de água do substrato foi ajustada para $70 \%$ da sua capacidade de retenção. A água utilizada foi previamente resfriada a $10^{\circ} \mathrm{C}$. Para reduzir a evaporação, as bandejas foram protegidas com saco plástico e, em seguida, transferidas para câmara fria a $10^{\circ} \mathrm{C}$ por 7 dias. Após o período de frio, as bandejas foram transferidas para germinadores (tipo M.A. 401 e "Seedburo"), com controle de temperatura $\left(25^{\circ} \mathrm{C}\right)$, umidade relativa (em torno de $100 \%$ ) e luz (24h), sendo as contagens realizadas aos 5 e 7 dias.

Teste de frio em bandejas, utilizando-se "terra" e papel toalha como substrato: as bandejas utilizadas foram as mesmas descritas no item anterior. No fundo da bandeja colocaram-se 22 folhas de papel toalha, umedecidas com quantidade de água equivalente a 2,5 vezes o seu peso. Em cada bandeja foram distribuídas 2 repetições de 50 sementes, em seguida cobertas com $1 \mathrm{~kg}$ de "terra". A disponibilidade de água do substrato, a temperatura, o período de frio e a germinação também corresponderam à descrição efetuada no item anterior.

Para os testes realizados em laboratório, a análise estatística foi efetuada utilizando-se o delineamento experimental inteiramente casualizado, com 5 tratamentos (lotes com diferentes níveis de vigor) e 4 repetições, para cada observação ou teste conduzido. Cada cultivar foi analisado separadamente. Para o teste de emergência das plântulas em campo, foi adotado o delineamento blocos ao acaso, com 5 tratamentos (lotes com diferentes níveis de vigor) e 4 repetições. Cada cultivar foi analisado separadamente. Para todos os testes foram feitas análises de variância e, a comparação de médias, realizada através do Teste de Tukey a $5 \%$.

\section{RESULTADOS E DISCUSSÃO}

Tanto na primeira, como na segunda época, as contagens de plântulas normais do teste de frio em bandejas, foram realizadas aos 5 e 7 dias. Como a classificação de lotes foi similar em ambas as avaliações, os dados apresentados referem-se apenas à contagem realizada aos 5 dias. Essa opção favoreceu a redução do período de avaliação das plântulas no teste de frio, proporcionando maior rapidez na obtenção dos resultados quando comparado com teste de frio utilizando-se "terra" em caixa. Embora a AOSA (1983), Burris (1990) e Hampton \& TeKrony (1995) recomendem a contagem de plântulas normais aos 4 dias para o teste de frio em bandejas, Cícero \& Vieira (1994) destacaram que a avaliação realizada aos 5 dias parece conduzir à obtenção de resultados mais consistentes.

De maneira geral, para todos os testes realizados e em ambos os cultivares, os coeficientes de variação obtidos foram relativamente baixos e aceitáveis para testes conduzidos em laboratório.

Para o cultivar AG 3010 , os resultados obtidos nos diferentes testes, encontram-se nas TABELAS 1 e 2, para a primeira e segunda épocas respectivamente.

Na primeira época (TABELA 1), observa-se que todos os testes de vigor identificaram o melhor desempenho dos lotes $C$ e $D$, não havendo diferenças significativas quanto à germinação. Para os demais lotes, notou-se que, no conjunto dos testes de vigor, os lotes $\mathrm{A}$, $B$ e $E$ mostraram potencial fisiológico inferior, sendo o pior desempenho do lote $B$ em relação aos demais, confirmado no teste de emergência das plântulas em campo.

Nas quatro categorias do teste de frio, quando 0 lote $E$ foi comparado com os lotes A e B (também de desempenho inferior), apesar de não haver diferenças

TABELA 1 - Grau de umidade e ao potencial fisiológico de cinco lotes de sementes de milho híbrido, cultivar AG 3010, avaliado pelos testes de germinação padrão, envelhecimento acelerado, emergência das plântulas em campo, teste de frio utilizando-se "terra" em caixas empilhadas, teste de frio utilizando-se "terra" em caixas dispostas lado a lado, teste de frio em bandeja utilizando-se apenas "terra" como substrato e teste de frio em bandeja utilizando-se folhas de papel toalha e "terra" como substrato. Resultados obtidos das análises efetuadas na primeira época.

Testes de frio

\begin{tabular}{|c|c|c|c|c|c|c|c|c|}
\hline Lote & $\begin{array}{l}\text { Grau de } \\
\text { Umidade }\end{array}$ & $\begin{array}{c}\text { Germinação } \\
\text { Padrão }\end{array}$ & $\begin{array}{l}\text { Envelhecimento } \\
\text { Acelerado }\end{array}$ & $\begin{array}{c}\text { Emergência } \\
\text { das plânt. } \\
\text { em campo }\end{array}$ & $\begin{array}{l}\text { "Terra" / caixas } \\
\text { empilhadas }\end{array}$ & $\begin{array}{l}\text { "Terra" / caixas } \\
\text { lado a lado }\end{array}$ & $\begin{array}{l}\text { Bandeja } \\
\text { "terra" }\end{array}$ & $\begin{array}{c}\text { Bandeja } \\
\text { "terra" + } \\
\text { papel }\end{array}$ \\
\hline & & & 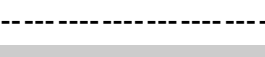 & - & 然 & 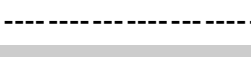 & & ------ \\
\hline A & 10,3 & $91,0 \mathrm{a}^{*}$ & $80,0 \mathrm{~b}$ & $93,0 \mathrm{ab}$ & $66,0 \mathrm{bc}$ & $64,0 \mathrm{~b}$ & $62,0 \mathrm{ab}$ & $67,0 \mathrm{ab}$ \\
\hline B & 11,2 & $90,0 \mathrm{a}$ & $77,0 \mathrm{~b}$ & $86,0 \mathrm{~b}$ & $79,0 \mathrm{ab}$ & $66,0 \mathrm{~b}$ & $61,0 a b$ & $65,0 \mathrm{ab}$ \\
\hline C & 10,5 & $96,0 \mathrm{a}$ & 97,0 a & $98,0 \mathrm{a}$ & 84,0 a & $83,0 \mathrm{a}$ & $73,0 \mathrm{a}$ & $71,0 \mathrm{ab}$ \\
\hline D & 10,4 & 96,0 a & $96,0 \mathrm{a}$ & $96,0 \mathrm{ab}$ & $88,0 \mathrm{a}$ & $75,0 \mathrm{ab}$ & 71,0 a & $74,0 \mathrm{a}$ \\
\hline$E$ & 10,2 & $92,0 \mathrm{a}$ & $88,0 \mathrm{ab}$ & $92,0 \mathrm{ab}$ & $65,0 \mathrm{c}$ & $62,0 \mathrm{~b}$ & $57,0 \mathrm{~b}$ & $57,0 \mathrm{~b}$ \\
\hline c.v. & & 4,6 & 7,3 & 6,6 & 7,0 & 7,2 & 6,9 & 8,0 \\
\hline
\end{tabular}

*Letras minúsculas: comparação de médias dentro de cada coluna. (Teste de Tukey, 5\%).

Scientia Agricola, v.57, n.3, p.459-466, jul./set. 2000 
significativas (exceto entre os lote $\mathrm{E}$ e B, para o teste de frio em caixas empilhadas) houve tendência de comportamento inferior para o lote $\mathrm{E}$, sendo que este apresentou médias numericamente mais baixas que as médias verificadas para os demais lotes. No entanto, no teste de envelhecimento acelerado e no teste de emergência das plântulas em campo, este lote apresentou bom desempenho. Assim, vários fatores podem ter influenciado os resultados. Conforme comentam Medina \& Marcos Filho (1990) um lote de sementes pode ser vigoroso em um aspecto, mas não em outros, dependendo do tipo de comportamento avaliado e/ou de estresses qualitativamente diferentes. Portanto, dentre os fatores que afetam os resultados do teste de frio podem ser destacados o grau de maturidade das sementes no momento da colheita (Rush \& Neal, 1951); danos causados pelas condições de armazenamento das sementes (Goodsell et al., 1955); danos causados por secagem excessiva (Loeffler et al., 1985; Martin et al., 1988); grau de umidade das sementes (Cal \& Obendorf, 1972); injúrias ao pericarpo (Tatum, 1954); tratamento de sementes (Meulen \& Henke, 1948; Hoppe, 1956). Dependendo da causa determinante da baixa qualidade das sementes, a resposta poderá ser mais ou menos drástica, dificultando a interpretação dos resultados (Marcos Filho et al., 1987).

Esses dados enfatizam a importância de se utilizar mais de um teste para a avaliação do potencial fisiológico das sementes. De acordo com Marcos Filho (1999), o uso de apenas um teste pode gerar informações incompletas. Por exemplo, no caso da presente pesquisa, se fossem considerados apenas os resultados obtidos no teste de frio, o lote E poderia ser classificado como o lote de pior qualidade; ou então, poderia ser descartado, se fosse 0 caso de um programa de controle de qualidade de uma empresa. Por outro lado, se fossem considerados apenas os testes de envelhecimento acelerado, germinação padrão e emergência das plântulas em campo, onde o lote E apresentou bom desempenho, sua deficiência em germinar e emergir em solo úmido e frio, não seria detectada; neste caso, se o lote fosse utilizado em condições desfavoráveis de campo (semelhantes as condições impostas pelo teste de frio), o prejuízo poderia ser significativo, em função da baixa porcentagem de emergência das plântulas. Assim, o conjunto de testes permitiu identificar os lotes $C$ e $D$ como de desempenho superior e, os lotes A e B, como de desempenho inferior, sendo o lote $E$ deficiente apenas nas condições de solo úmido e frio.

Com relação aos procedimentos utilizados para a condução do teste de frio, a classificação dos lotes foi considerada mais consistente nos métodos de "terra" em caixas dispostas lado a lado, bandejas com "terra" e bandejas com "terra" + papel, os quais acusaram desempenho inferior para os lotes $A, B$ e $E$, não revelando diferença significativa entre eles. Porém, no teste de frio em caixas empilhadas (menos drástico), o lote B mostrouse significativamente superior ao lote $E$ e também foi numericamente superior ao lote $A$, não havendo diferença significativa neste último caso. No entanto, ao relacionar os resultados com o teste de emergência das plântulas em campo, verifica-se desempenho inferior para o lote $\mathrm{B}$. Alguns trabalhos de pesquisa mostram que condições mais estressantes no teste de frio, tornam o procedimento mais eficiente em separar lotes de sementes de milho com diferentes níveis de potencial fisiológico (Molina et al., 1987; Medina \& Marcos Filho, 1990; Bruggink et al., 1991).

$\mathrm{Na}$ segunda época (TABELA 2) verifica-se que a diferença no comportamento dos lotes, pôde ser detectada mesmo no teste de germinação padrão, onde o lote C

TABELA 2 - Grau de umidade e ao potencial fisiológico de cinco lotes de sementes de milho híbrido, cultivar AG 3010, avaliado pelos testes de germinação padrão, envelhecimento acelerado, emergência das plântulas em campo, teste de frio utilizando-se "terra" em caixas empilhadas, teste de frio utilizando-se "terra" em caixas dispostas lado a lado, teste de frio em bandeja utilizando-se apenas "terra" como substrato e teste de frio em bandeja utilizando-se folhas de papel toalha e "terra" como substrato. Resultados obtidos das análises efetuadas na segunda época.

\begin{tabular}{|c|c|c|c|c|c|c|c|c|}
\hline \multirow[b]{2}{*}{ Lote } & \multirow[b]{2}{*}{$\begin{array}{l}\text { Grau de } \\
\text { Umidade }\end{array}$} & \multirow[b]{2}{*}{$\begin{array}{l}\text { Germinação } \\
\text { Padrão }\end{array}$} & \multirow[b]{2}{*}{$\begin{array}{c}\text { Envelhecimento } \\
\text { Acelerado }\end{array}$} & \multirow[b]{2}{*}{$\begin{array}{c}\text { Emergência } \\
\text { das plânt. } \\
\text { em campo }\end{array}$} & \multicolumn{4}{|c|}{ Testes de frio } \\
\hline & & & & & $\begin{array}{l}\text { "Terra" / caixas } \\
\text { empilhadas }\end{array}$ & $\begin{array}{l}\text { "Terra" / caixas } \\
\text { lado a lado }\end{array}$ & $\begin{array}{l}\text { Bandeja } \\
\text { "terra" }\end{array}$ & $\begin{array}{c}\text { Bandeja } \\
\text { "terra" + } \\
\text { papel }\end{array}$ \\
\hline & -------. n & - & - & 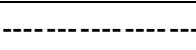 & of & - & - & - \\
\hline A & 10,7 & $90,0 b^{*}$ & $81,0 \mathrm{ab}$ & $83,0 \mathrm{c}$ & $60,0 \mathrm{~b}$ & $66,0 \mathrm{bc}$ & $69,0 \mathrm{~b}$ & $70,0 \mathrm{ab}$ \\
\hline B & 10,9 & $92,0 \mathrm{~b}$ & $77,0 \mathrm{~b}$ & $85,0 \mathrm{c}$ & $64,0 \mathrm{~b}$ & $68,0 \mathrm{bc}$ & $68,0 \mathrm{~b}$ & $63,0 \mathrm{bc}$ \\
\hline C & 10,8 & 99,0 a & $95,0 \mathrm{a}$ & $97,0 \mathrm{a}$ & $82,0 \mathrm{a}$ & $82,0 \mathrm{a}$ & $82,0 \mathrm{a}$ & 78,0 a \\
\hline D & 11,5 & $95,0 \mathrm{ab}$ & $93,0 \mathrm{a}$ & $95,0 \mathrm{ab}$ & $60,0 \mathrm{~b}$ & $79,0 a b$ & $72,0 \mathrm{ab}$ & $72,0 \mathrm{ab}$ \\
\hline$E$ & 11,3 & $93,0 \mathrm{ab}$ & $90,0 \mathrm{ab}$ & $88,0 \mathrm{bc}$ & $64,0 \mathrm{~b}$ & $64,0 \mathrm{c}$ & $62,0 \mathrm{~b}$ & $52,0 \mathrm{c}$ \\
\hline c.v. & & 6,1 & 8,4 & 6,0 & 4,5 & 6,5 & 5,5 & 6,6 \\
\hline
\end{tabular}

*Letras minúsculas: comparação de médias dentro de cada coluna. (Teste de Tukey, $5 \%$ ).

Scientia Agricola, v.57, n.3, p.459-466, jul./set. 2000 
mostrou desempenho significativamente superior aos lotes $\mathrm{A}$ e B. O teste de envelhecimento acelerado revelou potencial fisiológico mais elevado para os lotes $C$ e $D$, sendo o lote $B$ significativamente inferior a esses dois lotes. Os lotes $A$ e $E$, embora não apresentassem diferença significativa, também mostraram diferenças quando comparados aos lotes C e D. Nas quatro categorias do teste de frio, verificou-se desempenho superior para o lote $\mathrm{C}$. Novamente, o teste de frio em caixas empilhadas não apresentou resultados consistentes com os dos outros procedimentos e, também, com os resultados dos testes de germinação padrão, envelhecimento acelerado e emergência das plântulas em campo. O teste de frio em caixas empilhadas não detectou diferenças significativas entre os lotes A, B, D e E, sendo que o lote $D$ mostrou média numericamente inferior à do lote $\mathrm{E}$, o qual apresentou potencial fisiológico mais baixo nos demais procedimentos do teste de frio. No teste de frio em bandeja com "terra", o lote $D$ também não apresentou diferença significativa quando comparado com o lote $E$, mas apresentou média superior, indicando potencial fisiológico mais elevado.

No teste de frio em caixas dispostas lado a lado, teste de frio em bandeja com "terra" e em bandeja com "terra" + papel, os lotes A, B e E foram, em geral, deficientes. O teste de emergência das plântulas em campo, confirmou a menor qualidade desses três lotes, especialmente para os lotes $A$ e $B$. Na primeira época (TABELA 1), os lotes $A, B$ e $E$ também mostraram qualidade inferior, principalmente o lote $B$ que teve o pior desempenho em campo.

Considerando o conjunto de testes de vigor utilizados para a avaliação do potencial fisiológico do cultivar AG 3010, tanto na primeira como na segunda época, verifica-se que o teste de frio em caixas empilhadas não apresentou a mesma consistência de resultados observada para os demais testes, colocando em dúvida a qualidade do lote $B$ na primeira época e do lote $D$ na segunda época.

Em avaliações preliminares, verificou-se que no sistema de caixas empilhadas, há estratificação de temperatura do substrato entre as caixas, durante as primeiras horas de resfriamento. Outro ponto a ser destacado é que, neste sistema, a fase de embebição das sementes ocorre sob temperaturas mais elevadas. Talvez, esses fatores possam ter contribuído para a discrepância desses resultados em relação aos dos demais procedimentos do teste de frio, nos quais houve resfriamento mais rápido e uniforme do substrato. Burris (1990) cita que a injúria causada pelo resfriamento durante o período de embebição é uma característica fundamental do teste de frio; assim, cuidados devem ser tomados para garantir o rápido resfriamento do substrato (para $10^{\circ} \mathrm{C}$ ), permitindo que a embebição ocorra uniformemente a baixas temperaturas. Nas avaliações preliminares desta pesquisa, verificou-se também que, no método da bandeja, a temperatura de $10^{\circ} \mathrm{C}$ (ou menor) foi atingida 1 hora após a instalação do teste, para o procedimento que envolve o uso de "terra" e papel toalha e, 2 horas após, para o procedimento que utiliza apenas "terra" como substrato. O teste de frio, em caixas dispostas lado a lado, apesar de apresentar resfriamento mais rápido e uniforme do substrato, quando comparado com o teste de frio em caixas empilhadas, atingiu a temperatura de $10^{\circ} \mathrm{C}$ aproximadamente 10 horas após a instalação do teste.

As vantagens do teste de frio em bandeja, encontradas na presente pesquisa, estão de acordo com as observações feitas por Burris (1990), onde o método, além de ser mais eficiente (menos tempo por teste), permite avaliação rápida e precisa das plântulas e, também, maior grau de controle das condições ambientais.

Os resultados obtidos para o cultivar AG 5011, encontram-se nas TABELAS 3 e 4, para a primeira e segunda épocas, respectivamente.

Os dados referentes à primeira época (TABELA 3), mostram diferenças acentuadas no potencial fisiológico dos cinco lotes avaliados. Todos os testes, inclusive o de germinação padrão, classificaram os lotes A, D e E como os de pior desempenho embora nem sempre com diferenças significativas. No teste de emergência das plântulas em campo, onde as condições de ambiente eram favoráveis, apenas o lote $\mathrm{E}$ teve desempenho nitidamente inferior ao dos demais. Apesar de não haver diferença significativa entre os lotes $\mathrm{B}$ e $\mathrm{C}$, os testes de envelhecimento acelerado, de frio com "terra" em caixas dispostas lado a lado, os conduzidos em bandeja com "terra" e bandeja com "terra" + papel, também detectaram tendência do lote $C$ apresentar desempenho ligeiramente inferior ao observado para o lote B.

Apesar de não haver diferença significativa, os testes de emergência das plântulas em campo, teste de frio com "terra" em caixas empilhadas e em caixas dispostas lado a lado, detectaram diferenças entre os lote $D$ e $E$, sendo que este último apresentou qualidade inferior; porém, esses mesmos testes não acusaram o declínio de vigor do lote C (com exceção do teste de frio com "terra", em caixas dispostas lado a lado). O teste de frio em bandeja com "terra" + papel, ao contrário dos três testes citados, classificou o lote $\mathrm{D}$ como menos vigoroso.

Comparando os quatro procedimentos do teste de frio, verifica-se, que de maneira geral, todos detectaram diferenças entre os cinco lotes, destacando-se maior eficiência para o teste de frio em bandeja com "terra" e em bandeja com "terra" + papel, ao identificar diferenças no potencial fisiológico dos lotes B e C. Esses lotes apresentaram alto potencial fisiológico e a mesma germinação no teste padrão.

Segundo Delouche \& Baskin (1973), a perda da capacidade germinativa é o último evento característico do processo de deterioração das sementes. Assim, lotes de sementes que possuem germinação compatível com os padrões para comercialização e apresentam qualidade semelhante no teste de germinação, requerem uma análise mais sensível para avaliar o potencial de desempenho. 
TABELA 3 - Grau de umidade e ao potencial fisiológico de cinco lotes de sementes de milho híbrido, cultivar AG 5011, avaliado pelos testes de germinação padrão, envelhecimento acelerado, emergência das plântulas em campo, teste de frio utilizando-se "terra" em caixas empilhadas, teste de frio utilizando-se "terra" em caixas dispostas lado a lado, teste de frio em bandeja utilizando-se apenas "terra" como substrato e teste de frio em bandeja utilizando-se folhas de papel toalha e "terra" como substrato. Resultados obtidos das análises efetuadas na primeira época.

Testes de frio

\begin{tabular}{|c|c|c|c|c|c|c|c|c|}
\hline \multirow[b]{2}{*}{ Lote } & \multirow[b]{2}{*}{$\begin{array}{l}\text { Grau de } \\
\text { Umidade }\end{array}$} & \multirow[b]{2}{*}{$\begin{array}{l}\text { Germinação } \\
\text { Padrão }\end{array}$} & \multirow[b]{2}{*}{$\begin{array}{c}\text { Envelhecimento } \\
\text { Acelerado }\end{array}$} & \multirow[b]{2}{*}{$\begin{array}{c}\text { Emergência } \\
\text { das plânt. } \\
\text { em campo }\end{array}$} & \multicolumn{4}{|c|}{ Testes de frio } \\
\hline & & & & & $\begin{array}{c}\text { "Terra" / caixas } \\
\text { empilhadas }\end{array}$ & $\begin{array}{l}\text { "Terra" / caixas } \\
\text { lado a lado }\end{array}$ & $\begin{array}{l}\text { Bandeja } \\
\text { "terra" }\end{array}$ & $\begin{array}{c}\text { Bandeja } \\
\text { "terra" + } \\
\text { papel }\end{array}$ \\
\hline A & 10,5 & $92,0 a b^{*}$ & $79,0 \mathrm{~b}$ & $96,0 \mathrm{a}$ & $87,0 \mathrm{ab}$ & $76,0 \mathrm{bc}$ & $82,0 \mathrm{ab}$ & $64,0 \mathrm{~b}$ \\
\hline$B$ & 10,5 & 99,0 a & 98,0 a & 98,0 a & $95,0 \mathrm{a}$ & $91,0 \mathrm{a}$ & $87,0 \mathrm{a}$ & 77,0 a \\
\hline C & 10,5 & $99,0 \mathrm{a}$ & $94,0 \mathrm{a}$ & $98,0 \mathrm{a}$ & $97,0 \mathrm{a}$ & $89,0 \mathrm{ab}$ & $83,0 \mathrm{ab}$ & $73,0 a b$ \\
\hline D & 10,2 & $82,0 \mathrm{~b}$ & $76,0 \mathrm{~b}$ & $92,0 \mathrm{ab}$ & $81,0 \mathrm{~b}$ & $73,0 \mathrm{bc}$ & $74,0 \mathrm{~b}$ & $62,0 \mathrm{~b}$ \\
\hline$E$ & 10,4 & $85,0 \mathrm{~b}$ & $75,0 \mathrm{~b}$ & $85,0 \mathrm{~b}$ & $73,0 \mathrm{~b}$ & $66,0 \mathrm{c}$ & $73,0 \mathrm{~b}$ & $69,0 a b$ \\
\hline c.v. & & 7,2 & 4,3 & 6,3 & 7,3 & 8,7 & 5,4 & 5,8 \\
\hline
\end{tabular}

*Letras minúsculas: comparação de médias dentro de cada coluna. (Teste de Tukey, $5 \%$ ).

TABELA 4 - Grau de umidade e ao potencial fisiológico de cinco lotes de sementes de milho híbrido, cultivar AG 5011, avaliado pelos testes de germinação padrão, envelhecimento acelerado, emergência das plântulas em campo, teste de frio utilizando-se "terra" em caixas empilhadas, teste de frio utilizando-se "terra" em caixas dispostas lado a lado, teste de frio em bandeja utilizando-se apenas "terra" como substrato e teste de frio em bandeja utilizando-se folhas de papel toalha e "terra" como substrato. Resultados obtidos das análises efetuadas na segunda época.

\begin{tabular}{|c|c|c|c|c|c|c|c|c|}
\hline \multirow[b]{2}{*}{ Lote } & \multirow[b]{2}{*}{$\begin{array}{l}\text { Grau de } \\
\text { Umidade }\end{array}$} & \multirow[b]{2}{*}{$\begin{array}{c}\text { Germinação } \\
\text { Padrão }\end{array}$} & \multirow[b]{2}{*}{$\begin{array}{c}\text { Envelhecimento } \\
\text { Acelerado }\end{array}$} & \multirow[b]{2}{*}{$\begin{array}{c}\text { Emergência } \\
\text { das plânt. em } \\
\text { campo }\end{array}$} & \multicolumn{4}{|c|}{ Testes de frio } \\
\hline & & & & & $\begin{array}{l}\text { "Terra" / } \\
\text { caixas } \\
\text { empilhadas }\end{array}$ & $\begin{array}{c}\text { "Terra" / } \\
\text { caixas } \\
\text { lado a lado }\end{array}$ & $\begin{array}{l}\text { Bandeja } \\
\text { "terra" }\end{array}$ & $\begin{array}{c}\text { Bandeja } \\
\text { "terra" + } \\
\text { papel }\end{array}$ \\
\hline & & - & 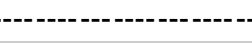 & \% & - & - & 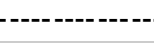 & ---- \\
\hline A & 11,0 & $90,0 b^{*}$ & $82,0 \mathrm{~b}$ & $91,0 \mathrm{~b}$ & $79,0 \mathrm{bc}$ & $71,0 \mathrm{~b}$ & $80,0 \mathrm{ab}$ & $63,0 \mathrm{~b}$ \\
\hline B & 10,8 & 99,0 a & $97,0 \mathrm{a}$ & 99,0 a & $95,0 \mathrm{a}$ & $88,0 \mathrm{a}$ & $87,0 \mathrm{a}$ & $80,0 \mathrm{a}$ \\
\hline C & 11,4 & 99,0 a & $98,0 \mathrm{a}$ & $97,0 \mathrm{a}$ & $88,0 a b$ & $86,0 \mathrm{a}$ & $81,0 \mathrm{ab}$ & $79,0 \mathrm{a}$ \\
\hline D & 11,1 & $80,0 \mathrm{~b}$ & $79,0 \mathrm{~b}$ & $82,0 \mathrm{~b}$ & $77,0 \mathrm{bc}$ & $74,0 \mathrm{~b}$ & $76,0 \mathrm{~b}$ & $74,0 a b$ \\
\hline $\mathrm{E}$ & 11,0 & $83,0 \mathrm{~b}$ & $84,0 \mathrm{~b}$ & $83,0 \mathrm{~b}$ & $65,0 \mathrm{c}$ & $73,0 \mathrm{~b}$ & $76,0 \mathrm{~b}$ & $65,0 \mathrm{~b}$ \\
\hline c.v. & & 5,8 & 6,0 & 4,8 & 9,3 & 6,4 & 4,9 & 5,9 \\
\hline
\end{tabular}

*Letras minúsculas: comparação de médias dentro de cada coluna. (Teste de Tukey, 5\%).

Portanto, é nessas condições que os testes de vigor devem ser utilizados (Hampton \& Coolbear, 1990). De maneira geral, para ambos os cultivares estudados, praticamente todos os lotes possuíam germinação compatível com os padrões para comercialização de sementes de milho.

Com relação aos dados obtidos na segunda época (TABELA 4), verifica-se que a classificação dos lotes seguiu a mesma tendência observada na época anterior (TABELA 3), principalmente para o teste de frio em bandeja com "terra". Diferenças mais acentuadas foram observadas para o teste de emergência das plântulas em campo, onde os lotes A e D mostraram pior desempenho em relação ao verificado na primeira época.
Na segunda época, o teste de frio com "terra" em caixas empilhadas, detectou diferenças de vigor entre os lotes B e C; o mesmo não foi observado para os testes de frio em bandeja com "terra" + papel e de envelhecimento acelerado, onde as respostas desses dois lotes foram semelhantes. Vale lembrar que, na primeira época, essa tendência foi detectada pelos referidos testes. Talvez a diferença entre os lotes B e C, não tenha sido detectada no teste de emergência das plântulas em campo, porque a queda de vigor do lote $C$ não foi tão acentuada e, também, porque as condições de ambiente durante a condução do teste eram favoráveis, o que acabou permitindo um bom desempenho do lote $C$. Já no teste de frio em caixas dispostas lado a lado, que detectou 
diferenças entre os lotes $D$ e $E$ na primeira época, houve agrupamento de médias na segunda época.

Considerando todos os testes realizados para a avaliação do potencial fisiológico do cultivar AG 5011, tanto na primeira como na segunda época, o teste de envelhecimento acelerado e o procedimento do teste de frio em bandejas utilizando-se apenas "terra" como substrato, foram os mais consistentes, permitindo a reprodutibilidade dos resultados e se relacionando com 0 teste de emergência das plântulas em campo. Entre os procedimentos adotados para o teste de frio, foi o que apresentou menor coeficiente de variação, em ambas as épocas. Burris \& Navratil (1979) também observaram relações dos resultados do teste de frio, obtidos pelo método da bandeja, com os de emergência das plântulas em campo. Os autores verificaram que o menor coeficiente de variação $(1,99 \%)$ foi obtido com o método da bandeja, que utiliza folhas de papel Kimpak + 500g de "terra" como substrato.

A reprodutibilidade dos resultados é o principal requisito desejado para um teste destinado à avaliação da qualidade das sementes, para permitir a comparação consistente dos resultados (AOSA, 1983; Hampton \& Tekrony, 1995). Porém, características como relação com a emergência das plântulas em campo, rapidez, objetividade, simplicidade de execução e viabilidade econômica, são também de fundamental importância para que um teste de vigor possa ser utilizado rotineiramente em um programa de controle de qualidade. Delouche (1976) cita que a padronização da metodologia e a da interpretação dos resultados, também são aspectos fundamentais.

De maneira geral, comparando os quatro procedimentos do teste de frio, verifica-se maior eficiência para os procedimentos de "terra" em caixas dispostas lado a lado, em bandeja com "terra" e em bandeja com "terra" + papel. O teste em caixas empilhadas, além de apresentar estratificação de temperatura do substrato durante as primeiras horas de resfriamento, revelou deficiências na classificação dos lotes, principalmente para o cultivar AG 3010.

Apesar do teste de frio, em caixas dispostas lado a lado, ter apresentado a mesma eficiência que os dois procedimentos do teste de frio em bandeja, para separar lotes com diferentes níveis de vigor, apresenta o inconveniente de ocupar mais espaço no interior da câmara fria e também da necessidade de resfriamento do substrato antes da instalação do teste. Para empresas e/ ou instituições que avaliam grande quantidade de amostras e que adotam o teste de frio como teste de rotina para a avaliação do potencial fisiológico das sementes, esses fatores se constituiriam entraves para o setor de controle de qualidade.

Embora existam alguns trabalhos citando a necessidade do controle da umidade relativa como uma desvantagem para o método da bandeja, neste experimento, o controle deste fator e, também, da temperatura do ambiente onde as sementes foram colocadas para germinar foi importante para a padronização do teste e para a obtenção de resultados mais consistentes. $O$ ajuste desses dois parâmetros e, também, a utilização de camada menos espessa de "terra" promoveram um desenvolvimento mais rápido e uniforme das plântulas (permitindo a redução do período necessário para a avaliação das plântulas), além de possibilitarem a condução do teste em uma época do ano em que a temperatura ambiente geralmente é mais baixa. Os testes foram eficientes tanto quando as diferenças entre lotes eram mais estreitas, como quando eram mais amplas.

\section{CONCLUSÕES}

- A distribuição de menores quantidades de substrato, em bandejas, para a condução do teste de frio oferece maior facilidade de padronização que a utilização de "terra" em caixas, permitindo a obtenção de resultados mais consistentes, inclusive quanto à relação com emergência das plântulas em campo.

- O teste de frio em bandejas, utilizando-se apenas "terra" (2 kg) ou "terra" (1 kg) + papel toalha (22 folhas), com umidade do substrato ajustada para $70 \%$ da sua capacidade de retenção de água, seguido por germinação conduzida em ambiente controlado de temperatura, umidade relativa e luz, pode ser utilizado com segurança para a avaliação do potencial fisiológico das sementes de milho.

\section{REFERÊNCIAS BIBLIOGRÁFICAS}

ASSOCIATION OF OFFICIAL SEED ANALYSTS. Seed vigor testing handbook. s.I.: AOSA, 1983. 88p. (Contribution. $\mathrm{n}^{\circ} 32$ to the Handbook on Seed Testing).

BRASIL. Ministério da Agricultura e da Reforma Agrária. Regras para análise de sementes. Brasília: SNDA,DNDV,CLAV, 1992. 365p.

BRUGGINK, H.; KRAAK, H.L.; BEKENDAM, J. Some factors affecting maize (Zea Mays L.) cold tests results. Seed Science and Technology, v.19, p.15-23, 1991.

BURRIS, J.S.; NAVRATIL, R.J. Relationship between laboratory cold-test methods and field emergence in maize imbreds. Agronomy Journal, v.71, p.985-988, 1979.

BURRIS, J.S. Recommended cold test procedure. Journal of Seed Technology, v.14, p.182-194, 1990.

CAL, J.P.; OBENDORF, R.L. Imbibitional chilling injury in Zea mays $\mathrm{L}$. altered by initial kernel moisture and maternal parent. Crop Science, v.12, p.369-373, 1972.

CÍCERO, S.M.; VIEIRA, R.D. Teste de frio. In: VIEIRA, R.D.; CARVALHO, N.M. Testes de vigor em sementes. Jaboticabal: FUNEP, 1994. p.151-164.

DELOUCHE, J.C. Standardization of vigor tests. Journal of Seed Technology, v.1, p.75-85, 1976.

DELOUCHE, J.C.; BASKIN, C.C. Accelerated aging techniques of predicting the relative storability of seed lots. Seed Science and Technology, v.1, p.427-452, 1973.

DIAS, M.C.L.L.; BARROS, A.S.R. Avaliação da qualidade de sementes de milho. Londrina: IAPAR, 1995. 43p. (Circular, 88).

GOODSELL, S.F.; HUEY, G.; ROYCE, R. The effect of moisture and temperature during storage on cold test reaction of Zea mays seed stored in air, carbon dioxide, or nitrogen. Agronomy Journal, v.47, p.61-64, 1955. 
HAMPTON, J.G.; COOLBEAR, P. Potential versus actual seed performance - can vigour testing provide an answer? Seed Science and Technology, v.18, p.215-228, 1990.

HAMPTON, J.G.; TEKRONY, D.M. Handbook of vigour test methods. 3.ed. Zurich: International Seed Testing Association, 1995. 117p.

HOPPE, P.E. Correlation between corn germination in laboratory cold tests and stands in the field. Plant Disease Reporter, v.40, p.887-889, 1956.

KRZYZANOWSKI, F.C.; FRANÇA NETO, J.B.; HENNING, A.A. Relato dos testes de vigor disponíveis para grandes culturas. Informativo ABRATES, v.1, p.15-50, 1991.

LOEFFLER, N.L.; MEIER, J.L.; BURRIS, J.S. Comparison of two cold test procedures for use in maize drying studies. Seed Science and Technology, v.13, p.653-658, 1985.

MARCOS FILHO, J.; CICERO, S.M.; SILVA, W.R. Avaliação da qualidade das sementes. Piracicaba: FEALQ, 1987. 230p.

MARCOS FILHO, J. Testes de vigor: importância e utilização. In: KRZYZANOWSKI, F.C.; VIEIRA, R.D.; FRANÇA NETO, J.B. Vigor de Sementes: conceitos e testes. Londrina: ABRATES, 1999. p.1-1-1-21.
MARTIN, B.A.; SMITH, O.S.; O'NEIL, M. Relationships between laboratory germination tests and field emergence of maize inbreds. Crop Science, v.28, p.801-805, 1988.

MEDINA, P.F.; MARCOS FILHO, J. Avaliação da qualidade fisiológica das sementes de milho (Zea mays L.). Anais da ESALQ, v.47, p.47-70, 1990.

MEULEN, V.E.; HENKE, F. Cold testing of seed corn. Seed World, v.63, p.8-10, 1948.

MOLINA, J.C.; IRIGON, D.L.; ZONTA, E.P. Comparação entre metodologias de teste de frio na avaliação da qualidade fisiológica de sementes de milho (Zea mays L.). Revista Brasileira de Sementes, v.3, p.77-85, 1987.

RUSH, G.E.; NEAL, N.P. The effect of maturity and other factors on stands of corn at low temperatures. Agronomy Journal, v.43, p.112-116, 1951.

TATUM, L.A. Seed permeability and "cold-test" reaction in Zea mays. Agronomy Journal, v.46, p.8-12, 1954.

Recebido em 23.11.99 